NBER WORKING PAPER SERIES

INFLATION AND THE ROLE OF BONDS

IN INVESTOR PORTFOLIOS

Zvi Bodie

Alex Kane

Robert McDonald

Working Paper No. 1091

NATIONAL BUREAU OF ECONOMIC RESEARCH

1050 Massachusetts Avenue

Cambridge MA 02138

March 1983

This paper was prepared as part of the National Bureau of Economic Research Program in Financlal Markets and Monetary Economics and Project on the Changing Roles of Debt and Equity in Financing U.S. Capital Formation, which was financed by a grant from the American Council of Life Insurance. It was presented at the NBER Conference on Corporate Capital Structures in the U.S., in PaIm Beach, Florida, on January 6 and 7, 1983. Zvi Bodie is Associate Professor of Finance at Boston University School of Management and NBER Research Associate. Alex Kane and Robert McDonald are both Assistant Professors of Finance at Boston University School of Management. Robert McDonald is also an NBER Research Fellow. Any opinions expressed are those of the authors and not those of the National Bureau of Economic Research. 
NBER Working Paper \#1091

March 1983

Inflation and the Role of Bonds in Investor Portfolios

Abstract

This paper explores both theoretically and erpirically the role of nominal bonds of various maturities in investor portfolios in the U.S. One of its principal goals is to determine whether an investor who is constrained to limit his investment in bonds to a single portfolio of money-fixed debt instruments will suffer a serious welfare loss. Our interest in this question stems in part from the observation that many ermloyer-sponsored savings plans limit a participant's investment choices to two types, a common stock fund and a moneyfixed bond fund of a particular maturity. A second goal is to study the desirability and feasibility of introducing a market for index bonds (i.e. an asset offering a riskless real rate of return) in the U.S. capital markets.

The theoretical framework is Merton's (1971) continuous time model of consumption and portfolio choice. Our measure of the welfare gain or loss from a given change in the investor's opportunity set is the increment to current wealth needed to completely offset the effect of the change. A novel feature of our empirical approach is the method of deriving equilibrium risk premia on the various asset classes. We employ the variance-covariance matrix of real rates of return estimated from historical data in combination with "reasonable" assumptions about net asset supplies and the economy-wide average degree of risk aversion to derive numerical values for these risk premia. This procedure allows us to circumvent the formidable estimation problems associated with using historical means, which are negative during some subperiods.

Our main results are: (1) There can be a substantial loss in welfare for participants in savings plans offering a choice of only two funds, a diversified stock fund and an intermediate-tern bond fund. Most of this loss can be eliminated by introducing as a third option a money market fund. (2) The potential welfare gain from the introduction of private index bonds in the U.S. capital market is probably not large enough to justify the costs of innovation. The major reason for the small gain is that one month bills with their small variance of real returns are an effective substitute for index bonds.

Zvi Bodie, Alex Kane and Robert McDonald School of Management

Boston University

704 Commonwealth Avenue

Boston, MA 02215 


\section{Inflation and the Role of Bonds in Investor Portfolios.}

\section{Introduction}

The inflation of the past decade and a half has dispelled the notion that default-free nominal bonds are a riskless investment. Conventional wisdom used to be that the conservative investor invested principally in bonds, and the aggressive or speculative investor invested principally in stocks. Short-term bills were considered to be only a temporary "parking place" for funds awaiting investment in either bonds or stocks. Today many acadenics and practitioners in the fleld of finance have come to the view that for an investor who is concerned about his real rate of return, long-term nominal bonds are a risky investment even when held to maturity.

The alternative view that a policy of rolling-over short term bills might be a sound long-term investment strategy for the conservative investor has recently gained credibility. The rationale behind this view is the observation that for the past few decades, bills have yielded the least variable real rate of return of all the major investment instruments traded in U.S. financial markets. Stated a bit differently, the nominal rate of return on bills has tended to mirror changes in the rate of inflation so that their real rate of return has remained relatively stable as compared to stocks or longer term fixed-interest bonds.

This is, of course, not a coincidence. All market-determined interest rates contain an "inflation premium," which reflects expectations about the declining purchasing power of the money borrowed over the life of the loan. As the rate of inflation has increased in recent years, so too has the inflation premium built into interest rates. While long-term as well as short-term 
interest rates contain such a premium, conventional long-term bonds lock the investor into the current interest rate for the life of the bond. If long-term interest rates on new bonds subsequently rise as a result of unexpected inflation, the funds already locked in can be released only by selling the bonds on the secondary market at a price well below their face value. But if an investor buys only short-term bonds with an average maturity of about thirty days, then the interest rate he earns will lag behind changes in the inflation rate by at roost one month. For the investor who is concerned about his real rate of return, bills may therefore be less risky than bonds, even in the long run.

The main purpose of this paper is to explore both theoretically and empirically the role of nominal bonds of various matidities in investor portfolios. How important is it for the investor to diversify his bond holdings fully across the range of bond maturities? We provide a way to measure the importance of diversification, and this enables us to determine the value of holding stocks and a variety of bonds, for example, as opposed to following a less cumbersome investment strategy, such as concentrating in stocks and bills alone.

One of our principal goals is to determine whether an investor who is constrained to limit his investment in bonds to a single portfolio of moneyfixed debt instruments will suffer a serious welfare loss. In part, our interest in this question stems from the observation that many employersponsored tax-deferred savings plans limit a participant's investment choices to two types, a common stock fund and a money-fixed bond fund of a particular maturity $\cdot^{1}$ 
A second goal is to study the desirability of introducing a market for indexed bonds (i.e. an asset offering a riskless real rate of return). There is a substantial literature on this subject, ${ }^{2}$ but to our knowledge no one has attempted to measure the magnitude of the welfare gain to an individual investor from the introduction of trading in such securities in the U.S. capital market. In the first part of the paper we develop a mean-variance model for measuring the value to an investor of a particular set of investment instruments as a function of his degree of risk aversion, rate of time preference and investment time horizon. We then take monthly data on real rates of return on stocks, bills and U.S. government bonds of eight different durations, their covariance structure, and combine these estimates with reasonable assumptions about net asset supplies and aggregate risk aversion in order to derive a set of equilibrium risk premia. This procedure allows us to circumvent the formidable problems of deriving reliable estimates of these risk premia from the historical means, which are negative during many subperiods. We then erploy these parameter values in our model of optimal consumption and portfolio selection in order to address the two empirical issues of principal concern to us. The paper concludes with a section summarizing the main results and pointing out possible irplications for private and public policy. 


\section{Theoretical Model}

\section{A. Model Structure and Assumptions}

Our basic model of portfolio selection is that of Markowitz (1952) as extended by Merton (1969 and 1971). Merton has shown that when asset prices follow a Geometric Brownian Motion in continuous time and portfolios can be continuously revised, then as in the original Markowitz model, only the means, variances and covariances of the joint distribution of returns need to be considered in the portfolio selection process.

In more formal terms we assume that the real return dynamics on all $\mathrm{n}$ assets are described by stochastic differential equations of the form:

$$
\frac{d Q_{i}}{Q_{i}}=R_{i} d t+\sigma_{i} d z_{i} \quad i=1, \ldots, n
$$

where $R_{i}$ is the mean real rate of return per unit time on asset $i$ and $\sigma_{i}^{2}$ the variance per unit time. For notational convenience we will let $\mathrm{R}$ represent the $n-v e c t o r$ of means and 3 the $n \times n$ covariance matrix, whose diagonal elements are the variances $\sigma_{i}^{2}$ and whose off-diagonal elements are the covariances $\sigma_{i j}$.

Investors are assumed to have homogeneous expectations about the values of these parameters. Furthermore, we assume that all $\mathrm{n}$ assets are continuously and costlessly traded and that there are no taxes. 3

The change in the individual's real wealth in any instant is given by:

$$
d w={ }_{1}^{n} w_{i} R_{i} d t-C d t+\underset{1}{w \Sigma_{w} \sigma_{i} d z}{ }_{i}
$$

where $W$ is real wealth, $C$ is the rate of consumption, and $w_{i}$ is the proportion of his real wealth invested in asset $i$. 
The individual's optimal consumption and portfolio rules are derived by finding:

$$
\max _{\{C, W\}} E_{0} \int_{0}^{H} e^{-p t} U\left(C_{t}\right) d t
$$

where $E$ is the expectation operator, $\rho$ is the rate of time preference, $U\left(C_{t}\right)$ is the utility from consumption at time $t$, and $H$ is the end of the investor's planning horizon.

The individual's derived utility of wealth function is defined as:

$$
J\left(w_{t}\right)=\max E_{t} \int_{t}^{H} e^{-p s} U\left(c_{s}\right) d s
$$

$J$ is interpreted as the discounted expected value of lifetime utility, sonditional upon the investor's following the rules for optimal consumption and portfolio behavior. This value can be computed as a function of current wealth. The specific utility function with which we have chosen to work is the wellknown constant relative risk aversion form:

$$
\begin{array}{ll}
U(c)=\frac{c^{\gamma}}{\gamma} & \text { for } \gamma<1 \text { and } \gamma \neq 0 \\
& \log c \quad \text { for } \gamma=0
\end{array}
$$

with $\delta \equiv 1-\gamma$ representing Pratt's measure of relative risk aversion. This functional form has several desirable properties for our purposes. First, the investor's degree of relative risk aversion is independent of his wealth, which in turn implies that the optimal portfolio proportions are also independent of wealth. Secondly, actually solving the problem in (2) allows us to find an explicit solution for the derived utility of wealth function (Merton 1971), which takes the relatively simple form: 
(4)

$$
\begin{aligned}
& J(W)=q \frac{W^{\gamma}}{\gamma} \\
& \text { where } q=\left\lfloor\frac{1-e^{-H\left(\frac{\rho-\gamma \nu}{\delta}\right)}}{\frac{\rho-\gamma \nu}{\delta}}\right\rfloor^{\delta}
\end{aligned}
$$

and $\nu$ is a nurber which reflects the parameters of the investor's investment opportunity set and his degree of risk aversion. ${ }^{4}$ Specifically, when there is no risk-free asset, $v$ is defined by:

$$
\nu=\frac{A}{G}+\frac{D}{2 G \delta}-\frac{\delta}{2 G}
$$

where

$$
\begin{aligned}
& A \equiv i^{\prime} \Omega^{-1} R \\
& B \equiv R^{\prime} \Omega^{-1} R \\
& G \equiv S^{-1} i \\
& D \equiv B G-A^{2}
\end{aligned}
$$

where $i$ is a vector of dimension $n$ all of whose elements are 1.

The degree of relative risk aversion plays an important role in the specific numerical results which follow, so we interpret this parameter by means of a simple exarale. Suppose an individual faces a situation in which there is a .5 probability of losing a proportion $x$ of his current wealth and a .5 probability of gaining the same proportion. What proportion of current wealth would the individual be willing to pay as an insurance premium in order to eliminate this risk? ${ }^{5}$

Table 1 displays the value of this insurance premium for various values of $x$ and $\delta$. The second row, for example, shows that for a risk which involves a gain or loss of $10 \%$ of current wealth an investor with a coefficient of relative 
Table 1: Proportion of Current Wealth an Investor

Would Be Willing to Pay to Avoid a Risky

Prospect with a Payof $f$ of $\mp \times x W$

(percent of wealth)

\begin{tabular}{|c|c|c|c|c|c|c|c|}
\hline $\begin{array}{l}\text { Proportion of } \\
\text { Wealth at Risk }\end{array}$ & \multicolumn{7}{|c|}{ Coefficient of Relative Risk Aversion $(\delta)$} \\
\hline $\mathbf{x}$ & 1 & 2 & 3 & 4 & 5 & 6 & 10 \\
\hline $1 \%$ & $.005 \%$ & $.010 \%$ & $.015 \%$ & $.020 \%$ & $.025 \%$ & $.030 \%$ & $.050 \%$ \\
\hline $10 \%$ & $0.50 \%$ & $1.00 \%$ & $1.49 \%$ & $1.97 \%$ & $2.43 \%$ & $2.88 \%$ & $4.42 \%$ \\
\hline $20 \%$ & $2.02 \%$ & $4.00 \%$ & $5.86 \%$ & $7.56 \%$ & $9.06 \%$ & $10.35 \%$ & $13.84 \%$ \\
\hline $50 \%$ & $13.40 \%$ & $25.00 \%$ & $32.92 \%$ & $37.76 \%$ & $40.72 \%$ & $42.61 \%$ & $46.00 \%$ \\
\hline
\end{tabular}


risk aversion of 1 would only pay one half of one per cent of his wealth (or $5 \%$ of the magnitude of the possible loss) to insure against 1t, while an investor with a $\delta$ of 10 would pay $4.42 \%$ of his wealth (which is fully $44.2 \%$ of the magnitude of the possible loss). If the investor with a $\delta$ of 10 faces a risky prospect involving a possible gain or loss of $50 \%$ of his wealth, he would be willing to pay $92 \%$ of the possible loss to avold the risk.

B. Optimal Portfolio Proportions and Equillbrium Risk Premia

The vector of optimal portfolio weights derived from the optimization model described above is given by:

$$
w^{*}=\frac{1}{\delta} \Omega^{-1}\left(R-\frac{A}{G} i\right)+\frac{\Omega^{-1} i}{G}
$$

Note that these weights are independent of the investor's rate of time preference and his investment horizon. Merton (1972) has shown that $\frac{A}{G}$ is the mean rate of return on the minimum variance portfolio and that $\frac{\Omega^{-1} \dot{I}}{G}$ is the vector of portfolio weights of the $n$ assets in the minimum variance portfolio. Denoting these by $R_{m i n}$ and $w_{m i n}$, respectively, we can rewrite equation (6) as:

$$
w^{*}=\frac{1}{\delta} \Omega^{-1}\left(R-R_{\min } 1\right)+w_{\min }
$$

The demand for any individual asset can thus be decomosed into two parts represented by the two terms on the right hand side of equation (7): 


$$
w_{i}^{*}=\frac{l}{\delta} \sum_{j=1}^{n} v_{i j}\left(R_{j}-R_{\text {min }}\right)+w_{i, m i n}
$$

where $v_{i j}$ is the $i j^{\text {th }}$ element of $\Omega^{-1}$, the inverse of the covariance matrix. The first of these two parts is a "speculative demand" for asset $i$, which depends inversely on the investor's degree of risk aversion and directly on a weighted sum of the risk prenia on the $n$ assets. The second cormonent is a "hedging demand" for asset $i$ which is that asset's weight in the minimum-variance portfolio. 6

Under our assumption of homogeneous expectations the equilibrium risk premia on the $n$ assets are found by aggregating the individual demands for each asset (equation $6^{\prime}$ ) and setting ther equal to the supplies. The resulting equilibrium yield relationships can be expressed in vector form as:

$$
R-R_{\min } i=\bar{\delta}\left(s_{i} w_{M}-c_{m i n}^{2} i\right)
$$

where $\bar{\delta}$ is a harmonic mean of the individual investors' measures of risk aversion weighted by their shares of total wealth, $w_{M}$ is the vector of net supplies of the $n$ assets each expressed as a proportion of the total value of all assets, and $\sigma^{2}$ min is the variance of the minimam variance portfolio.

The portfolio whose weights are given by $\mathrm{w}_{M}$ has come to be known in the literature on asset pricing as the "market" portfolio, and we will adopt that same terninology here. Equation (8) implies that: 
(9)

$$
R_{i}-R_{\text {min }}=\vec{\delta}\left(\sigma_{i M}-\sigma_{m i n}^{2}\right) \quad i=1, \ldots, n
$$

where $\sigma_{i M}$ is the covariance between the real rate of return on asset $i$ and the rate of return on the market portfolio.

This relationship holds for any individual asset and for any portfolio of assets. Thus for the market portfolio we get:

$$
R_{M}-R_{\min }=\bar{\delta}\left(\sigma_{M}^{2}-\sigma_{m i n}^{2}\right)
$$

It is interesting to compare this with the traditional form of the Capital Asset Pricing Model which assumes the existence of a riskless asset. In that special case $R_{m i n}$ is simply the riskless rate and $\sigma^{2}$ min is zero.

By substituting the equilibrium values of $R_{i}-R_{\text {min }}$ from equation (8) into equation ( $\left.6^{\prime}\right)$, we get for investor $k$ :

$$
w_{k}^{*}=\frac{\delta}{\delta_{k}} w_{M}+\left(1-\frac{\bar{\delta}}{\delta_{k}}\right) w_{\min }
$$

This implies that in equilibrium every investor will hold some combination of the market and the minimum variance portfolios. If the investor is more risk averse than the average he will divide his portfolio into positive positions in both the market portfolio and the minimu variance portfolio, with a higher proportion in the latter the greater his degree of risk aversion. If he is less risk averse than the average he will sell the minimum variance portfolio short in order to invest more than 100 percent of his funds in the market portfolio. 


\section{The Welfare Loss frora Incomplete Diversification}

Suppose the investor faces an investment opportunity set consisting of less than the full set of $n$ assets. How rach additional current wealth would he have to be given in order to make him as well off as he was with the full set of n assets?

Let $J(W \mid n)$ be the lifetime utility of an investor who chooses from among $n$ assets, and let $J(W \mid n-m)$ be the lifetime utility of an investor choosing from among a restricted set of assets. Let $W$ represent the investor's actual level of current wealth and $\hat{W}$ the level at which his welfare would be the same under the restricted opportunity set. $\hat{\mathrm{W}}$ is defined by:

$J(W \mid n)=J(\hat{W} \mid n-m)$

Thus $\hat{W}-W$ is the extra wealth necessary to compensate the investor for having a restricted opportunity set and is greater than or equel to zero. From equation (4) we get:

$$
\hat{W}=W\left[\frac{\perp 1-e^{-H\left(\frac{\rho-\gamma v}{\delta}\right)}}{(\rho-\gamma v)} \cdot \frac{(\rho-\gamma \hat{v})}{\left\lfloor 1-e^{-H\left(\frac{\rho-\gamma \hat{v}}{\delta}\right)}\right\rfloor}\right\rfloor^{\gamma}
$$

where $\hat{v}$ is calculated according to equation (5) and corresponds to the restricted opportunity set. 7

Equation (12) implies that the magnitude of the welfare loss will in general depend on the investor's risk aversion, $\delta$, rate of time preference, $\rho$, and investment horizon, H. Since $\hat{W}$ is proportional to $W$ a convenient measure of this loss, which is independent of the investor's wealth level, is $\frac{\hat{W}}{W}-1$, the loss per dollar of current wealth. Since $\hat{W} \geq W$, this number is always greater than or equal to zero. 
Of course, certain restrictions on the investment opportunity set need not decrease investor welfare. We know from equation (11) that even if the investor had only two matual funds to choose from, there would be no loss in welfare, provided they were the market portfolio and the minimum variance portfolio. Merton (1972) has shown that any two portfolios along the mean-variance portfolio frontier would serve as well. But, in general, restricting the number of assets in the opportunity set does lead to a loss in investor welfare.

D. The Shadow Riskless Rate and the Gain from Introducing a Riskless Asset We define the shadow riskless real rate of interest as that rate at which an investor would have no change in welfare if his opportunity set were expanded to include a riskless asset. When the investment opportunity set includes a riskless asset, Merton (1971) shows that the lifetime utility of wealth function is the same as (4), except that $\nu$ is replaced by $\lambda$, where:

$$
\lambda=R_{F}+\frac{\left(R-R_{F} i\right) \cdot \Omega^{-1}\left(R-R_{F} i\right)}{2 \delta}
$$

We find the expression for the shadow riskless rate by setting $v$ equal to $\lambda$, and solving for $R_{F}$. This gives:

$$
R_{F}=R_{\min }-\delta \sigma^{2} \min
$$

This implies that a risk averse investor will always have a shadow riskless real rate which is less than the mean real return on the minimu variance portfolio. The return differential is equal to his degree of relative risk aversion times the variance of the minimum variance portfolio. 
If there is a zero net supply of this riskless asset in the econory, the equilibrium value of $R_{F}$ will just be $R_{\text {min }}-\bar{\delta}_{\sigma_{\text {min }}^{2}}^{2}$. Therefore, by assumption, an investor with average risk aversion will not gain from the introduction of a market for index bonds. For an investor whose risk aversion is different from the average there will be a welfare gain, ignoring the costs of establishing and operating such a market. We measure this gain analogously to the way we measured the welfare cost of incomplete diversification in the previous section.

As before, let $W$ be the investor's actual level of wealth and $\hat{W}$ the level at which his welfare would be the same under an opportunity set expanded to include a riskless asset offering a real rate of $\mathrm{R}_{\text {min }}-\bar{\delta}^{2}$ min . Since in this case $\hat{W} \leq W$, we take as our measure of the welfare gain from indexation $1-\frac{\hat{W}}{W}$ or the amount the investor would be willing to give up per dollar of current wealth for the opportunity to trade index bonds. 
III. The Data and Parameter Estimates

In this section we will describe our data and how we used them to estimate the parameters needed in evaluating the welfare loss from restricting an investor's opportunity set and the gain from introducing a real riskless asset. It must be borne in mind that we were not trying to empirically test the model of capital market equilibrium presented in section II but rather to derive its implications for the specific questions being addressed in this paper. It was therefore important to maintain consistency between the underlying theoretical model and the parameter estimates derived from the historical data, even if that meant ignoring some of the descriptive statistics yielded by those data.

Our raw data were monthly real rates of return on stocks, one-month U.S. Government Treasury Bills, and eight different U.S. bond portfolios. We used monthly data in order to best approximate the continuous trading assumption of Merton's model, and because one month is the shortest interval for which information about the rate of inflation is avallable. The measure of the price level that we used in computing real rates of return was the Bureau of Labor Statistics' Consumer Price Index, excluding the cost-of-shelter component. We excluded the cost of shelter component because it gives rise to well-known distortions in the measured rate of inflation.

The bill data are from Tbbotson and Sinquefield (1982), while the bond data are from the U.S. Government Bond File of the Center for Research in Security Prices (CRSP) at the University of Chicago. The stock data are from the CRSP monthly NYSE file. We divided the bonds into eight different portfolios based on duration. We felt that duration was superior to maturity as a 
criterion for grouping the bonds since it takes into account a bond's coupon as well as its maturity. ${ }^{8}$ The durations of the bond portfolios range from one to eight years.

Table 2 presents the means, variances and correlation coefficients of the monthly real rates of return on the ten asset categories for three subperiods between January 1953 and December 1981. The first is the twelve years from January 1953 to December 1964, a period of relative price stability; the second is the eight years from 1965 to 1972, a period of moderate inflation; and the third is the nine years from 1973 to 1981, a period of relatively rapid inflation.

The measure of the real rate of return used in all cases was the natural logarithm of the monthly real wealth relatives $Q_{i}(t) / Q_{i}(t-1)$. On the assumption that these returns follow a geometric Brownian motion in continuous time:

$$
d Q_{i} \mid Q_{i}=R_{i} d t+\sigma_{i} d z_{i}
$$

the log of the wealth relative over a discrete time interval is normally distributed with mean $\mu_{i}$ and variance $\sigma_{i}{ }^{2}$, where

$$
\mu_{i}=R_{i}-\frac{\sigma_{i}^{2}}{2} .
$$

The means reported in Table 2 were converted to annual rates by multiplying them by 12 and the standard deviations by multiplying them by $\sqrt{12}$. This makes them comparable to the means and standard deviations one would obtain using a one year holding period. 
Table 2: Distribution of Monthly Real Rates of Return (annualized)

A. 1953-1964

\begin{tabular}{|c|c|c|c|c|c|c|c|c|c|c|}
\hline & Common & Imonth & & & onds ( $b$ & oy dure & tion $i$ & in year & rs) & \\
\hline & Stocks & Bills & 1 & 2 & 3 & 4 & 5 & 6 & 7 & 8 \\
\hline Mean & .1202 & .0113 & .0183 & .0213 & .0218 & .0151 & .0188 & .0122 & .0074 & .0243 \\
\hline $\begin{array}{l}\text { Standard } \\
\text { Deviation }\end{array}$ & .1179 & .0081 & .0105 & .0170 & .0235 & .0268 & .0311 & .0305 & .0361 & .0155 \\
\hline $\begin{array}{l}\text { Number of } \\
\text { Observations }\end{array}$ & 144 & 144 & 144 & 144 & 144 & 144 & 138 & 110 & 84 & 42 \\
\hline$\frac{\text { Correlation }}{\text { Coefficients: }}$ & & & & & & & & & & \\
\hline $\begin{array}{l}\text { Stocks } \\
\text { B11ls } \\
\text { Bonds } 1 \\
\\
2 \\
3 \\
4 \\
5 \\
6 \\
7 \\
7\end{array}$ & & .04 & $\begin{array}{r}-.02 \\
.70\end{array}$ & $\begin{array}{r}-.09 \\
.40 \\
.81\end{array}$ & $\begin{array}{r}-.10 \\
.25 \\
.70 \\
.85\end{array}$ & $\begin{array}{r}-.06 \\
.23 \\
.68 \\
.82 \\
.90\end{array}$ & $\begin{array}{r}-.13 \\
.22 \\
.65 \\
.78 \\
.83 \\
.86\end{array}$ & $\begin{array}{r}-.15 \\
.24 \\
.65 \\
.80 \\
.82 \\
.86 \\
.88\end{array}$ & $\begin{array}{r}-.12 \\
.25 \\
.56 \\
.74 \\
.80 \\
.83 \\
.86 \\
.91\end{array}$ & $\begin{array}{l}.15 \\
.42 \\
.63 \\
.59 \\
.60 \\
.65 \\
.79 \\
.75 \\
.95\end{array}$ \\
\hline
\end{tabular}

B. $1965-1972$

\begin{tabular}{lrrrrrrrrrr} 
& $\begin{array}{l}\text { Common } \\
\text { Stocks }\end{array}$ & Bills & 1 & 2 & 3 & 4 & 5 & 6 & 7 & 8 \\
\hline Mean & .0413 & .0122 & .0162 & .0179 & .0101 & .0007 & .0032 & .0078 & .0339 & .0113 \\
$\begin{array}{l}\text { Standard } \\
\text { Deviation }\end{array}$ & .1345 & .0064 & .0155 & .0298 & .0370 & .0427 & .0519 & .0427 & .0453 & .0377 \\
$\begin{array}{l}\text { Number of } \\
\text { Observations }\end{array}$ & 96 & 96 & 96 & 96 & 96 & 96 & 96 & 52 & 30 & 6
\end{tabular}

Correlation

\section{Coefficients:}

$\begin{array}{llllllllll}\text { Stocks } & .11 & .25 & .33 & .38 & .33 & .33 & .08 & .03 & .23 \\ \text { Bills } & & .64 & .52 & .37 & .38 & .27 & .32 & .38 & 0 \\ \text { Bonds 1 } & & & .86 & .78 & .74 & .67 & .69 & .60 & .11 \\ 2 & & & & .83 & .80 & .73 & .76 & .77 & .98 \\ 3 & & & & & .82 & .84 & .85 & .86 & .57 \\ 4 & & & & & & .83 & .86 & .49 & .41 \\ 5 & & & & & & & .94 & .77 & .61 \\ 6 & & & & & & & & .66 & .72 \\ 7 & & & & & & & & & .88\end{array}$




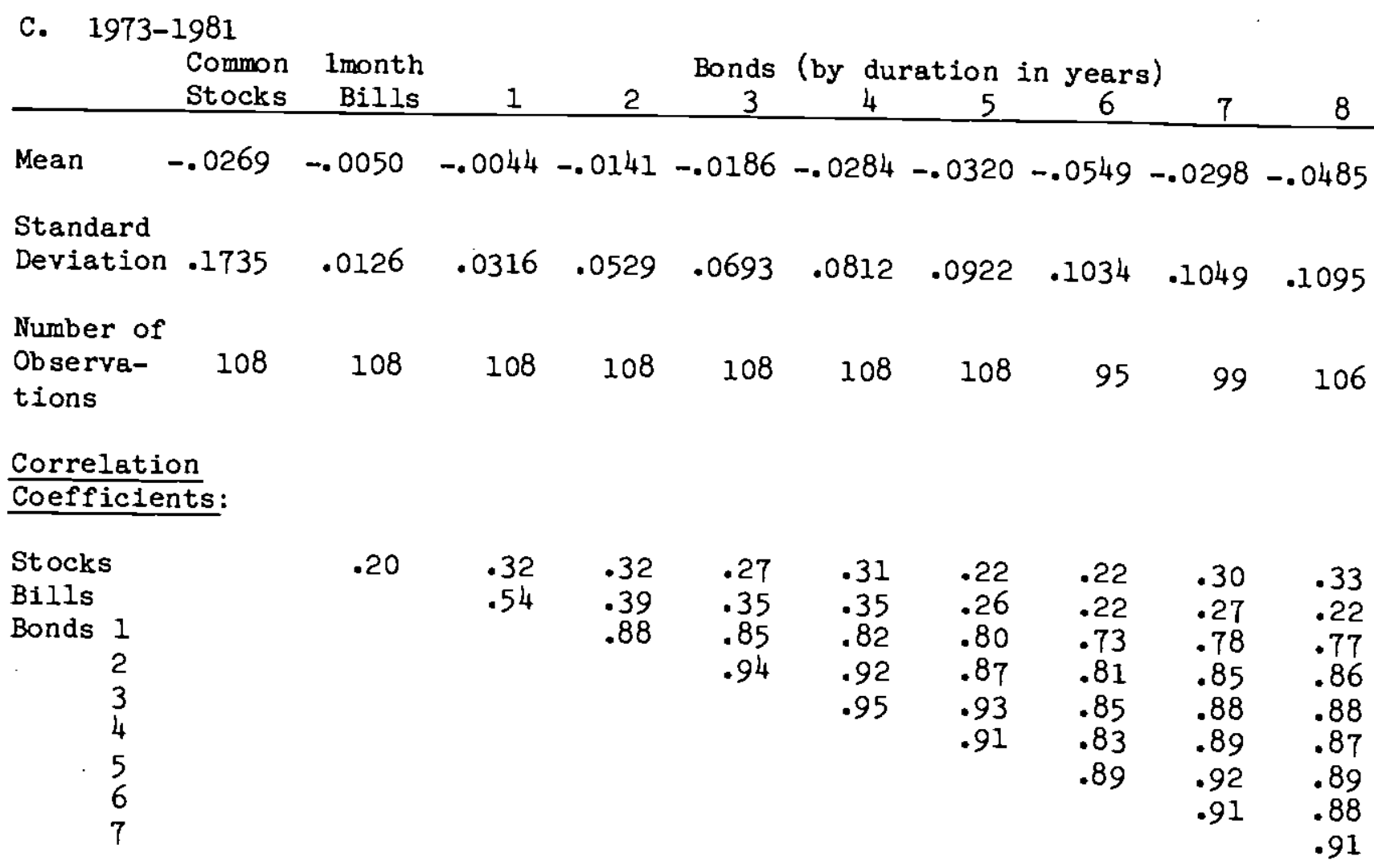

Notes: The measure of the real rate of return used is the natural logarithm of the monthly real wealth relative. The reported means were converted to annual rates by multiplying them by 12 and the standard deviations by multiplying them by $\sqrt{12}$. This makes them comarable to the means and standard deviations of the continuously compounded rates of return one would obtain using a one year holding period. 
A most striking aspect of these descriptive statistics can be seen in part $C$ of the table: all assets have negative mean returns over the last subperiod. This presents a dilemm for anyone requiring estimates of the risk premia called for in models of capital market equilibrium, since their recent historical pattern is grossly inconsistent with the pattern implied by the variance-covariance matrix estimated from the same data.

As Merton (1980) has shown, in order to get a reliable estimate of the mean of a continuous tine stochastic process, it is necessary to observe the process over a long span of time. Variances and covariances, however, can be measured fairly accurately over rach shorter observation periods. We therefore chose to ignore the historical means reported in Table 2, while using the estimated covariance matrix.

The standard deviations of all ten assets reported in Table 2 increased significantly over the three periods. Since we were interested in computing welfare losses and gains for investors in today's U.S. capital markets, we used In our calculations the variances and correlation coefficients estimated for the most recent period, $1973-1981$.

The standard deviations for this last subperiod fall into a clear pattern. The lowest is for bills, .0126, which is well below that on 1 year bonds, the next lowest reported in the table. The standard deviation on bonds rises continuously with duration, reaching a maximu of .1095 on duration 8 . Stocks have a standard deviation of .1735 , which is 1.6 times that of duration 8 bonds and about 14 times that of bills. In the previous two subperiods, while all the standard deviations are lower than in the 1973-1981 subperiod, they fall into approximately the same pattern of relative magnitudes. 
Turning to the matrix of correlation coefficients, we see that in the last subperiod all of the correlations are positive. Stocks had correlations ranging from .20 (with bills) to .33 (with duration 8 bonds), and they do not rise unfformly with the duration of the bonds. The pattern for bonds and bills is that correlations are highest among bonds of adjacent durations and fall off more or less uniforinly as one moves to more distant durations. In the 1965-1972 subperiod the pattern of correlations is quite similar to 1973-1981 for all assets, but in the non-inflationary 1953-1964 subperiod the correlations among bills and bonds follow the same pattern, while the real returns on stocks appear to be essentially uncorrelated with the real returns on bills and bonds.

In addition to the variance-covariance matrix, the next input we need for equation (8) in order to generate numerical results is the vector of weights for the market portfolio. Here we face some problems of both a theoretical and an empirical sort.

At the theoretical level, one issue is whether to treat U.S. government bonds as net wealth. There is considerable controversy among monetary theorists on this issue and a substantial literature on it exists. 9 We decided to treat U.S. government debt as net wealth of the private sector.

We also ignore the default risk premium on corporate bonds by lumping them together with Treasury bonds. This amounts to assuming that they have the same variance-covariance structure.

Another problem is our exclusion of some important categories of assets In our computation of the market portfolio. Most notable among these is residential real estate, consumer durables, human capital and social security wealth. 10 While we do not include these in the present paper, our plan for 
future extensions of this research is to seek appropriate data on these other asset classes and redo our calculations to include them.

There remains the empirical problem of determining the relative weights of those assets which we do include in the market portfolio in the present study. The ratio of the market value of corporate equity to the book value of total government debt was approximately 1.5 in 1980 . Thus, 60\% was the equity welight in the market portfolio. The relative supplies of government debt by duration were approximated from a table in the Treasury Bulletin which breaks down the quantities of government debt by maturity: issues maturing in less than one year, in one to five years, and so forth. We arbitrarily spread the weights evenly among the years within each of these groupings.

This procedure obviously omits corporate debt. However, using Flow-of-Funds data we computed the percentage of equity by treating both corporate equity and the net worth of unincorporated businesses as equity. Debt then consisted of federal, corporate and unincorporated business credit market liabilities. This procedure also yielded a $60 \%$ equity to wealth ratio. By lumping corporate debt together with U.S. government debt we are ignoring any default risk premia.

The foregoing ignores financial intermediaries, in effect supposing that households hold the securities of non-financial businesses and the government directly. A different procedure would be to net out securities held by intermediaries, and consider the public's holding of bank liabilities as debt. (Deposits could be treated as treasury bills, for example.) we plan to experiment with this alternative in future research. 
The ultimate set of weights we used for the market portfolio was: Bonds by duration in years

$\begin{array}{cccccccccc}\text { Stocks } & \text { Bills } & 1 & 2 & 3 & 4 & 5 & 6 & 7 & 8 \\ .60 & .05 & .15 & .033 & .033 & .033 & .033 & .022 & .022 & .022\end{array}$

Finally, in order to determine the equilibrium risk premia we need to set a value for $\bar{\delta}$, the economy-wide average degree of relative risk aversion. In a recent paper Grossman and Shiller (1981) concluded that a value of 4 is most consistent with the observed movements of the value of the stock market over the past ninety years. Friend and Blume (1975) estimated it to be 2 , while Friend and Hasbrouck (1982) found 6 to be more appropriate. As we show below, a value of 4 produces an imputed risk premium on stocks which is in line with direct time series estimates of this premium obtained by other researchers using a variety of estimation techniques. We therefore choose 4 as our value for $\bar{\delta}$ in the calculation of the equilibrium risk premia which we use in the remainder of the paper. To a large extent the particular value of $\bar{\delta}$ is unimportant, since the deviation of $\delta_{k}$ from $\bar{\delta}$, and not the level, is what matters most for our results.

Table 3 presents the full set of imputed real risk premia $\left(R_{i}-R_{\text {min }}\right)$ which we calculated using the formala embodied in equation (8), the variancecovariance matrix of monthly real returns estimated over the period 1973-1981, and the vector of market weights and value of $\bar{\delta}$ presented above. The table also shows the individual asset variances, their covariances with the market portfolio and their betas on the market portfolio. The last two columns give the values corresponding to the minimum variance and market portfolios, respectively. 
Table 3: Imputed Risk Preria, Variances and Covariances with the Market Portfolio (annualized)

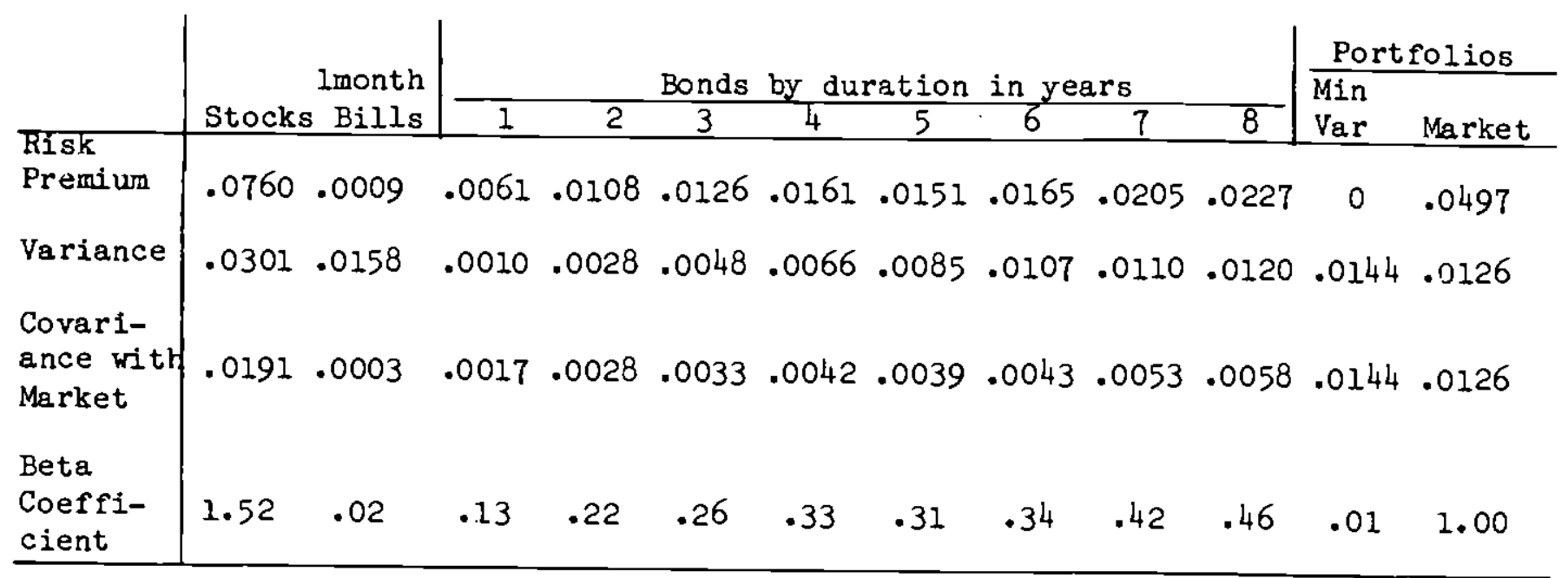

Notes: 1. The risk premia were computed according to the formula:

$$
R_{i}-R_{\min }=\bar{\delta}\left(\sigma_{i M}-\sigma_{\min }^{2}\right)
$$

with $\bar{\delta}$, the econom-wide average coefficient of relative risk aversion set equal to 4 ; the $\sigma$ are the covariances with the market portfolio reported in the third row of the table.

2. The variances and covariances reported above were computed from the distribution of the natural logs of the monthly real wealth relatives. They were annualized by multiplying them by 12 .

3. The reported beta coefficients are the covariance with the market divided by the variance of the market portfolio. 
The table shows that the real risk premium on the market portfolio is approxinately $5 \%$ per year, which is almost four times its variance of $1.26 \%$ per year. Since we have set $\delta$ at 4 , the risk premium on the market portfolio would be exactly 4 times its variance if the variance of the minimu variance portfolio were zero rather than $.0144 \%$ per year. The risk premium on bills is only 9 basis points, and the variance is only slightly higher than the minimum, which is not surprising since as we shall see in the next section the minimum variance portfolio is essentially bills.

With the sole exception of duration 5 , the risk premia on bonds rise uniformly with duration reaching a maximum of $2.27 \%$ per year. Finally, the risk premium on stocks is $7.60 \%$ per year or approximately 1.5 times the risk premium on the market portfolio. Since the beta of stocks is approximately 1.5, this result should not be surprising to readers familiar with the Capital Asset Pricing Model. 11 It is also in line with the long run time series estimates derived by Tobotson and Sinquefield (1982) and Merton (1980). 
IV. The Welfare Loss from Incomplete Diversification

In this section we address the question of how much welfare an investor loses by having his choice of assets limited. The main conclusion of the theoretical discussion in part II was that even if an investor's opportunity set is limited to only two assets, there will be no loss in welfare provided that these two assets are the market portfolio and the minimum variance portfolio (or any other set of two frontier portfolios). But we are interested in the actual menu of asset choices offered in practice by many employer-sponsored taxsheltered savings plans in the U.S.. These plans usually offer participants a choice of two or three funds: a stock fund, an intermediate-term fixed-interest bond fund, and sometimes as a third option a money market fund.

Table 4 presents the risk prenia, variances and asset compositions of the optimal portfolios chosen from the full set of ten assets for investors with coefficients of relative risk aversion ranging from 2 to 10 . Figure 1, which is the familiar efficient portfolio frontier, displays graphically the meanvariance combinations tabulated in the second and third columns of Table 4. The middle row of Table 4 corresponds to the market portfolio and the last row to the minimum variance portfolio, which consists essentially of bills, hedged with small offsetting short and long positions in bonds of the various durations. Table 4 shows that a very risk averse investor, with a coefficient of risk aversion of 6 , would hold $40 \%$ of his portfollo in stocks, $40 \%$ in bills and the remaining $20 \%$ in bonds of various durations. He would thereby attain a risk premium of about $3.3 \%$ per year with a variance of $.57 \%$ per year. Even an extremely risk averse investor, one whose $\delta$ value is 10 , would still invest roughly 24 percent of his funds in stocks, 67 percent in bills and the remainder 


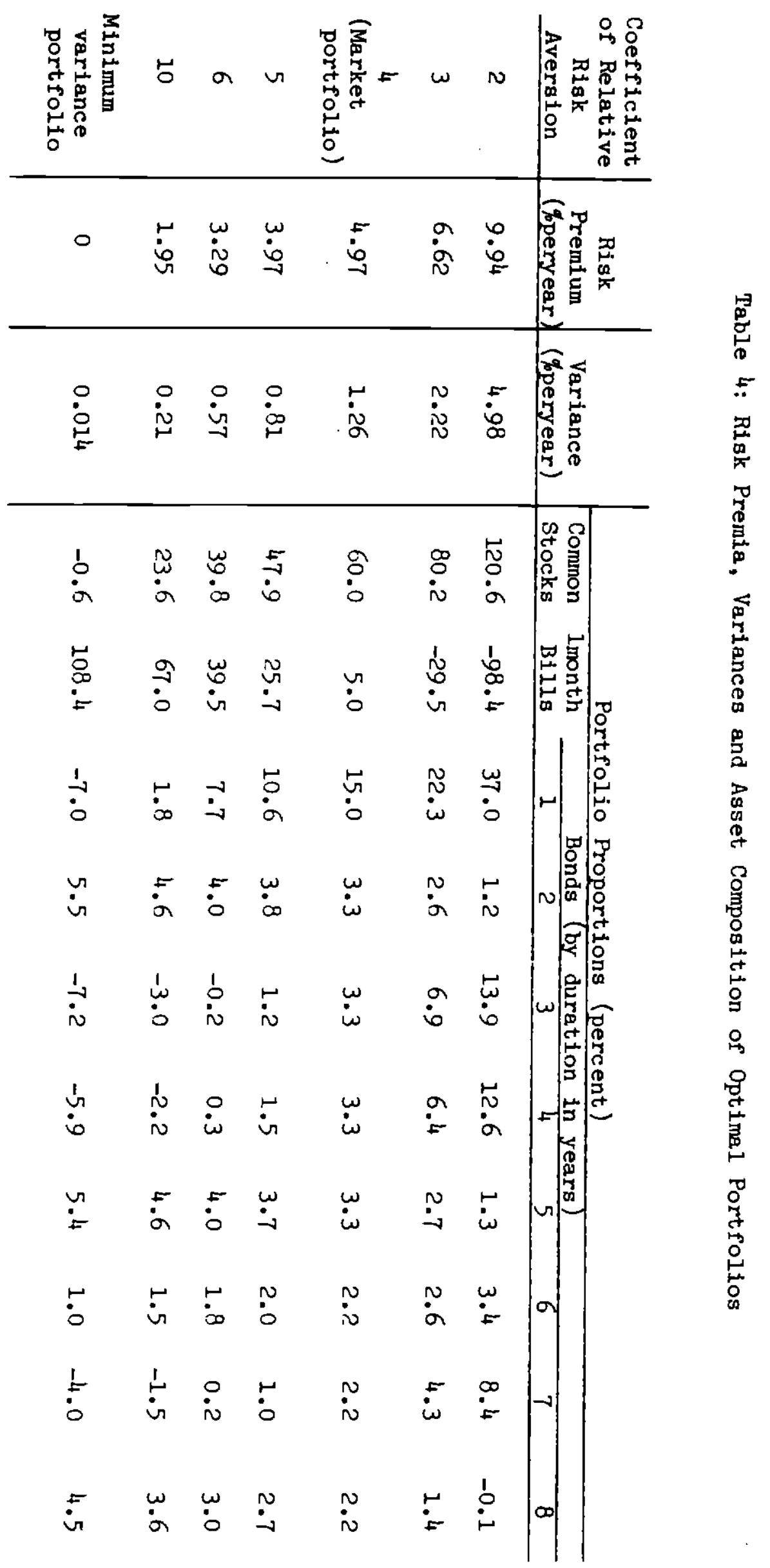


Figure 1 - Effledent Portfolio Fron:j:

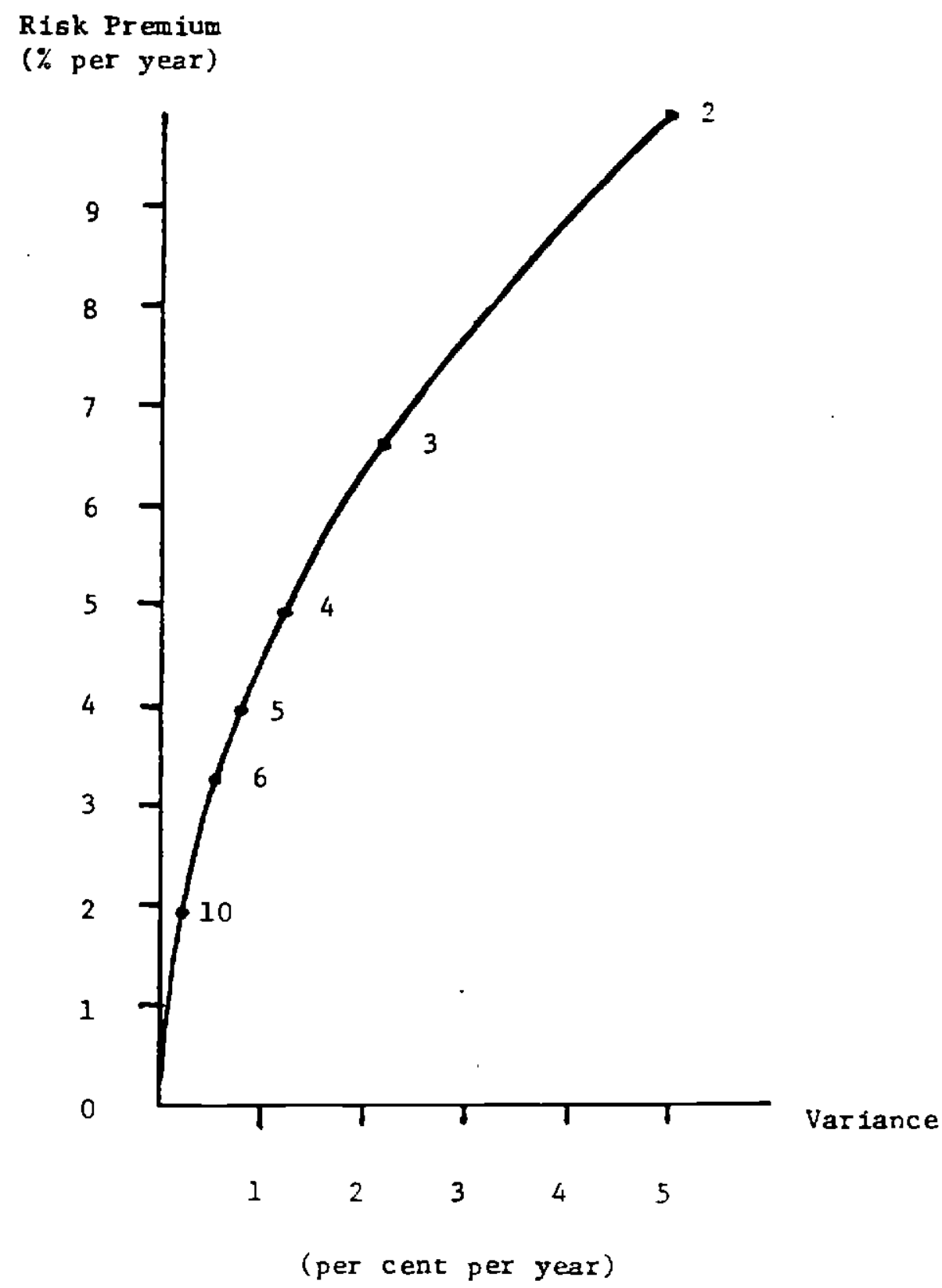

Source: Table 4.

Note: The numbers on the frontier are coefficients of relative risk aversion and indicate the point which would be optimal for an investor having the corresponding degree of risk aversion. 
in bonds of various durations, in order to attain a mean risk premium of $1.95 \%$ per year with a variance of only .21\% per year.

Note that for coefficients of relative risk aversion smaller than the econorg-wide average of 4 , the investor takes larger short positions in bills and long positions in stocks and bonds of most durations. In the first row, for example, we see that an investor with a risk aversion coefficient of 2 nearly doubles the mean risk premiur on his portfolio relative to the average investor, but also increases the variance by a factor of four.

Short-selling treasury bills is difficult in practice. This difficulty can be overcome in two ways. First, a large investment house or pension fund could allow its less risk-averse investors to short-sell to the more risk-averse investors, as a purely internal transaction. Second, and more likely, a less risk-averse investor can simply take a long position in stock market futures as a way to hold a levered position in stocks.

Table 5 and Figure 2 present our estimates of the welfare loss to an investor from having his opportunity set restricted to various subsets of the ten asset classes. The numbers in this table represent the amount of money the investor would need to be given per $\$ 10,000$ of his current wealth to make him as well off with the restricted choice set as he would be with the full set of ten assets. In order to do these calculations we had to determine the mean rates of return themselves, not just the risk premia. We did this by assuming that the mean on bills is zero and calibrating all other rates accordingly. This assumption was based on the actual mean real return on bills observed over the past 30 years. 
Figure 2 - Welfare Loss from Incomplete Diversificaticr.

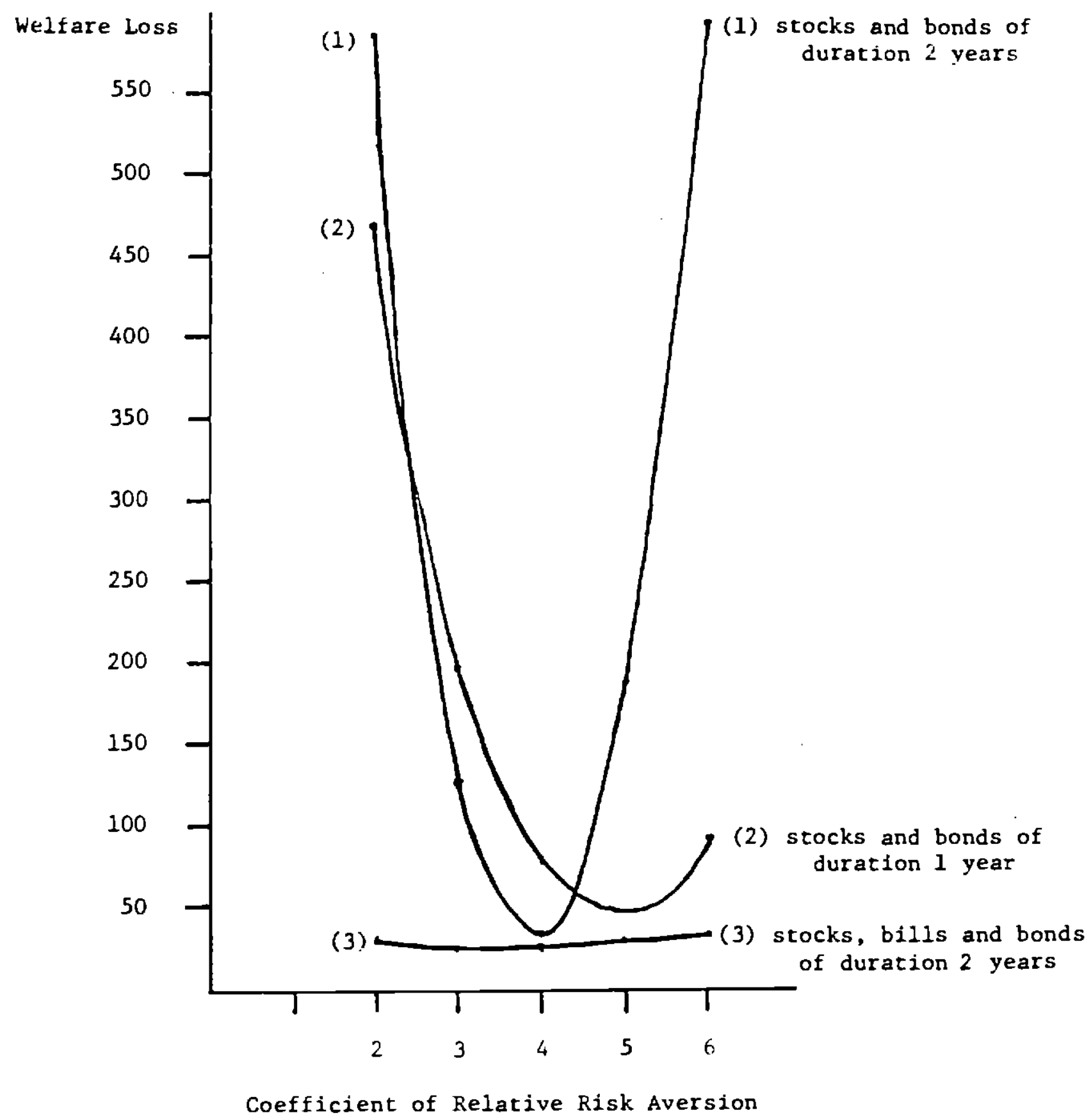

Source: Table 5 . 
We also had to assume a rate of time preference and a specific planning horizon. We arbitrarily set these at $4 \%$ per year and infinity, respectively, but did a sensitivity analysis which we report below in Table 6 . It should be noted that the infinite horizon assumption is really meant to represent the case where time of death is uncertain and the parameter $\rho$ in (2) incorporates the rate of mortality as in Merton (1971). Note also that Table 5 shows the welfare loss from restricting the investor's portfolio choice forever, not just for a limited period.

Table 5 and Figure 2 show that when the investor is restricted to only two assets, the welfare impact of the restriction can be quite sensitive to his coefficient of risk aversion. If the two assets are stocks and bonds of duration 2 years (curve 1), we see that the welfare loss is small for an investor with a risk aversion coefficient equal to the average, 4, but increases sharply on either side of this value. If, on the other hand, the two assets are stocks and bonds of duration 1 year (curve 2), then the welfare loss is greatest for the least risk averse investor, but is not extreme for any investor. Investors with coefficients of risk aversion equal to 3 or 4 are better off with stocks and bonds of duration 2 years, whereas investors who are either more or less risk averse than that would prefer stocks and bonds of duration 1 year.

A corparison of the first two columns in Table 5 reveals that stocks and bonds of duration one year are preferable to stocks and bills for all investors except those with risk aversion of 2. Moving across Table 5 we see that as the duration of the bond fund increases the welfare loss becomes more sensitive to the coefficient of risk aversion. Thus for bonds of duration 4 years the smallest welfare loss relative to the full 10 asset opportunity set occurs at a coefficient of risk aversion of 3 , rising quite sharply on either 
Table 5: Welfare Loss from Incomlete Diversification

(dollars per $\$ 10,000$ of wealth)

\begin{tabular}{|c|c|c|c|c|c|c|}
\hline \multirow{3}{*}{$\begin{array}{l}\text { Coefficient } \\
\text { of Relative } \\
\text { Risk Aversion }\end{array}$} & \multicolumn{5}{|c|}{2 Assets } & \multirow{3}{*}{$\begin{array}{l}3 \text { As sets } \\
\text { Stocks, bills } \\
\text { and bonds of } \\
\text { duration 2years }\end{array}$} \\
\hline & \multirow{2}{*}{$\begin{array}{l}\text { Stocks and } \\
\text { bills }\end{array}$} & \multicolumn{4}{|c|}{ Stocks and bonds of duration: } & \\
\hline & & lyear & 2years & 4years & 8years & \\
\hline 2 & $\$ 344$ & $\$ 468$ & $\$ 585$ & $\$ 713$ & $\$ 804$ & $\$ 29$ \\
\hline 3 & 279 & 197 & 128 & 65 & 44 & 27 \\
\hline 4 & 249 & 77 & 32 & 17 & 462 & 28 \\
\hline 5 & 231 & 46 & 186 & 27 & 2,090 & 30 \\
\hline 6 & 218 & 91 & 592 & 2,325 & 6,197 & 33 \\
\hline
\end{tabular}

₹

Notes: These estimates correspond to an assumed rate of time preference of $4 \%$ per year and an infinite horizon. In setting the mean rates of return we assumed that the mean on bills is zero and calibrated the others accordingly. 
side of that value and becoming particularly severe for very risk averse investors.

The last column in Table 5 shows that when the choice set is expanded from two to three assets, stocks, bills and bonds of duration two years, the magnitude of the welfare loss falls dramatically for all investors, regardless of their degree of risk aversion. Having these three assets to choose from is thus almost as good as having all ten.

The effects of changing our assumptions about the rate of time preference and the horizon are shown in Table 6. The magnitude of the welfare loss from restricting the choice set to stocks and bills is greater the lower the rate of time preference and the longer the horizon.

These numerical results suggest that if an employer-sponsored savings plan is going to restrict its participants to a choice of only two funds, then since the sponsor does not know the exact degree of risk aversion of the paticipants, it would make sense to let the two funds be stocks and bonds of duration 1 or 2 years. If, however, the sponsor is willing to expand the number of funds to three, then stocks, bills and bonds of duration two years will eliminate almost all of the welfare loss relative to the full ten asset opportunity set. The applicability of our analysis to employer-sponsored tax-deferred savings plans is limited by two factors: assets held outside the plan, and taxes. Without taxes it is trivially obvious that the omission of bills from a savings plan is of no consequence if investors can hold a money market fund on their own account. When there are tax advantages to investing in a savings plan, however, on the margin the investor prefers to hold assets inside the plan. If the plan fails to offer a full menu of assets, the investor will 
Table 6: Effect of Rate of Time Preference and

Time Horizon on the Welfare Loss from

Incomplete Diversification

(dollars per $\$ 10,000$ of wealth)

A. Rate of

time preference

2 Assets:

Stocks

0

and bills

$\$ 394$

$2 \%$ per year

305

$4 \%$ per year

249

Notes: Assumes a coefficient of risk aversion of 4 and an infinite time horizon.

2 Assets:

Stocks

B. Time horizon and bills

$\begin{array}{lc}1 \text { month } & \$ 0.28 \\ 5 \text { years } & 17 \\ \text { infinite } & 249\end{array}$

Notes: Assumes a rate of time preference of $4 \%$ per year. 
suffer a welfare loss. Our numerical calculations can be viewed as applying to a world in which all assets are invested in a tax-deferred savings plan with a restricted menu of assets. In general, however, our numerical calculations still provide an upper bound on the possible welfare loss, for the following reason: if the investor could in principle invest all wealth in the plan, and chooses not to do so, in order to diversify, then the welfare loss must be less than for an investor who is (as in our calculations) constrained to hold only those assets offered by the plan.

In practice, of course, additional complications reduce the importance of tax-deferred savings plans. The IRS imposes a limit on the contributions to these plans, and frequently there are penalties or delays associated with the premature withdrawal of funds. These considerations will reduce the percentage of an investor's wealth which is held in such savings plans. Therefore the failure of the plan to offer certain assets is less important, since freely chosen assets held outside the plan will undo the effect of restrictions imposed within the plan. Our numerical estimates again provide an upper bound on the welfare loss. 
V. Shadow Riskless Rates and the Welfare Gain from Introduction of a Riskless

$\underline{\text { Real Asset }}$

In part II we defined the shadow riskless rate of interest as that rate at which an investor would have a zero gain in welfare from having his choice set expanded to include an asset which was riskless in real terms. Equation (12) showed that this rate is below the mean real rate of return on the minimim variance portfolio by an amount equal to the investor's degree of relative risk aversion times the variance of the minimum variance portfolio. Given that our estimate of this variance is a mere $.0144 \%$ per year, it follows that even a very risk averse investor $(\delta=6)$ would be willing to give up less than 9 basis points.

Since the average degree of risk aversion is 4 , if a market for riskless real bonds could be established costlessly, the market clearing real interest rate would be about 6 basis points below the mean rate on the minimum variance portfolio. Table 7 shows what the welfare gain would be to investors with varying degrees of risk aversion.

The magnitude of the welfare gain to investors does not appear to be large. The numbers in the first column of Table 7 show the results obtained using the actual covariance matrix estimated for the 1973-1981 subperiod. The second column shows the results of an experiment in which we made all nominal debt securities twice as risky by doubling their variances and covariances, leaving the variance of stocks unchanged. While the effect is to approximately double the welfare gain to investors at any degree of risk aversion, the magnitude of the gain atill appears small. 
Table 7: Welfare Gain from Introduction of a Real Riskless Asset (dollars per $\$ 10,000$ of wealth)

\begin{tabular}{c|cc}
\multirow{2}{*}{\begin{tabular}{c} 
Coefficient of $\begin{array}{c}\text { Welfare Gain } \\
\text { Aversion }\end{array}$ \\
\cline { 2 - 3 } 2
\end{tabular}} & $\begin{array}{c}\text { Actual } \\
\text { Covariance } \\
\text { Matrix }\end{array}$ & $\begin{array}{c}\text { Double all variances \& } \\
\text { covariances but stocks }\end{array}$ \\
\hline 3 & $\$ 32$ & $\$ 63$ \\
4 & 7 & 13 \\
5 & 0 & 0 \\
6 & 6 & 12
\end{tabular}


These results suggest one possible reason for the nonexistence of index bonds in the U.S. capital market. Since there would probably be some costs associated with creating a new market for such bonds, the benefits would have to exceed those costs. Given the assumptions of our rodel, in particular the assumption of homogeneous expectations, the benefit from trading in index bonds would have to arise from differences in the degree of risk aversion among investors. If as Table 7 suggests, the welfare gain does not appear to be large over a fairly broad range of risk aversion coefficients, then one should not be surprised at the failure of a market for index bonds to appear.

One should bear in mind that Table 7 is derived assuming a zero net aggregate supply of index bonds. Thus it does not answer the question of whether the welfare gain from indexing government debt would be significant. 
VI. Summary and Discussion of Findings

We undertook this research with two main policy questions in mind: (1) Is there a significant welfare loss stemming from the practice on the part of many employer-sponsored savings plans of restricting a participant's choice of investments to two or three asset classes? (2) What is the potential welfare gain from the introduction of trading in privately issued index bonds? In this section we sumarize and discuss the implications of our findings for each.

With regar to the first of these, we have shown that there is no necessary loss of welfare from restricting an investor's choice set to only two funds, provided these two are properly chosen. If they are the market portfolio and the minimu variance portfolio, then there will be no loss at all. In practice, however, many plans offer a diversified common stock fund and an intermediate-term fixed-interest bond fund as the only two assets, and in such cases there can be a substantial welfare loss to participants whose degree of risk aversion differs appreciably from the average. Most of this loss can be elirinated for risk averse participants by introducing as a third option a money narket fund.

With regard to the second question, our results indicate that the potential welfare gain from the introduction of index bonds in the current U.S. capital market is probably not large enough to justify the costs of innovation. The major reason for the snall gain we calculate is the fact that one month bills with their small variance of real returns are an effective substitute for index bonds.

There are some important factors bearing on these two policy questions, which we either excluded or ignored in our analysis, and we need to at least 
consider their potential impact on our conclusions. The first is the fact that we limited ourselves to only a subset of the assets which individuals in the U.S. hold in their portfolios. Specifically, we excluded residential real estate, consumer durables, and nontradeable assets like human capital and social security wealth.

Undoubtedly the inclusion of these other assets would affect the magnitude of the welfare effects we calculated. Thus the welfare loss to an individual whose employer-sponsored savings plan offers only a stock fund and a bond fund would almost surely be smaller. The loss would appear smaller still, were we to take into account the fact that individuals have access to other assets outside of the plan. Nonetheless, it is probably still true to say that not having a money market option lowers the welfare of investors who are more risk averse than the average. Similarly, the small welfare gain from index bonds, which we calculated, would probably become even smaller, in the context of the broader spectrum of assets, especially when one considers that Social Security is indexed.

Our agenda for future research starts with a more detailed quantitative analysis of the impact of these additional assets. 


\section{Footnotes}

1. An example of particular relevance to acadenics is the plan managed by the Teachers Insurance and Annuity Association and of fered by many private educational institutions in the U.S. Under this plan the participant can choose between a common stock fund, the College Retirement Equities Fund (CREF), and a second fund which is essentially a portfolio of intermediate term nominal bonds.

2. See, for example, the paper by Fischer (1975) and the references cited therein.

3. All of these simplifying assumptions are, of course, counterfactual, and there is a considerable literature on the effect of relaxing each of them. The only one which we think would materially affect the main results in this paper is the no taxes assumption. We discuss its likely effects in section IV, p. 23.

4. A necessary condition for (4) to be correct is $\rho>\gamma \nu$. See Merton (1969).

5. Pratt (1964) shows that for small changes in wealth this insurance premium is approximately $1 / 2 \delta x^{2}$. Note that $x^{2}$ is the variance of the proportional change in wealth caused by the risky prospect.

6. See Bodie (1982) for a discussion in terns of nominal rates of return and unanticipated inflation.

7. Note that if $\frac{\rho-\underline{\nu}}{\delta}>0$ then as $H+\infty$ equation (12) reduces to:

$$
\hat{W}=U\left(\frac{\rho-\gamma \hat{v}}{\rho-\gamma \nu}\right)^{\frac{\delta}{\gamma}}
$$

8. Duration, as defined by Macaulay (1938) is a weighted average of the years to maturity of each of the cash flows from a security. The weights are the present value of each year's cash flow as a proportion of the total present value of the security. Duration equals final maturity only in the case of pure discount bonds. For coupon bonds and mortgages, duration is always less than maturity. The difference between maturity and duration for ordinary coupon bonds and mortgages is greater the longer the final maturity and the higher the level of interest rates. In our sample of bonds this difference rose steadily over the 1953-1981 period due to the rising trend in interest rates. The most pronounced differences were in the 8 year duration category. In 1953 the average maturity of the bonds in our 8 year duration portfolio was just under 9 years whereas in 1981 the average maturity of the 8 year duration portfolio was 23 years. This variation over the last 30 years calls into question the appropriateness of a bond return series with a constant maturity of 20 years, such as the one tabulated by Tbbotson and Sinquefield (1982). 
$-30-$

9. For the arguments on both sides of this debate see Burro (1974) and Robin $(1980)$.

10. Including residential real estate would raise another theoretical issue. Individual holdings of residential real estate serve both to diversify the portfolio and to hedge against changes in the relative price of housing services. This hedging demand is ignored in our model and including it would substantially increase the difficulty of solving for the $\mathrm{J}$ function.

11. Equation (9) in our model implies that:

$$
R_{i}-R_{\min }=\frac{\left(\sigma_{i M}-\sigma_{\min }^{2}\right)}{\left(\sigma_{M}^{2}-\sigma_{\min }^{2}\right)}\left(R_{M}-R_{\min }\right)
$$

Since $\sigma^{2} \min$ is very small relative to the covariance of stocks with the market and to the variance of the market, we get:

$$
R_{\text {stocks }}-R_{\text {min }} \cong B_{\text {stocks }}\left(R_{M}-R_{\text {min }}\right)
$$


References

Barro, R. 1974. Are Government Bonds Net Wealth? Journal of Political Econory.

Bodie, Z. 1982. Inflation Risk and Capital Market Equilibrium. The Financial Reviev. May.

Fischer, S. 1975. The Demand for Index Bonds. Journal of Political Econory. June.

Friend, I. and Blume, M. 1975. The Demand for Risky Assets. American Economic Review. December.

Friend, I. and Hasbrouck, J. 1982. Effect of Inflation on the Profitability and Valuation of U.S. Corporations. Proceedings of the Conference on Savings, Investment and Capital Markets in an Inflationary Environment, Szego and Sarnat, eds., Ballinger, 1982.

Grossman, S. and Shiller, R. 1981. The Determinants of the Variability of Stock Market Prices. American Economic Review. May.

Ibbotson, R.G. and Sinquefield, R.A. 1982. Stocks, Bonds, Bills and Inflation.

Macaulay, F.R. 1938. Some Theoretical Problems Suggested by the Movcenents of Interest Rates, Bond Yields, and Stock Prices in the U.S. since 1856. New York: National Bureau of Economic Research.

Markowitz, H. 1952. Portfolio Selection. Journal of Finance. March.

Merton, R.C. 1969. Lifetime Portfolio Selection Under Uncertainty: The Continuous-Tine Case. Review of Economics and Statistics. August.

- 1971. Optiraum Consumption and Portfolio kules in a ContinuousTime Model. Journal of Economic Theory. Decerber.

- 1972. An Analytic Derivation of the Efficient Portfolio Frontier. Journal of Financial and Quantitative Analysis. September.

- 1980. On Estimating the Expected Return on the Market: An Exploratory Investigation. Journal of Financial Economics. December.

Pratt, J.W. 1964. Risk Aversion in the Small and in the Large. Econometrica.

Tobin, J. 1980. As set Accumalation and Economic Activity. University of Chicago Press. 